\title{
Estudios Comparados
}

CIUDAD Y TERRITORIO

ESTUDIOS TERRITORIALES

ISSN(P): 2697-231X; ISSN(E): 2697-2328

Vol. LIII, N.ำ Monográfico 2021

Págs. 217-238

https://doi.org/10.37230/CyTET.2021.M21.13

CC BY-NC-ND

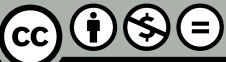

Porcentajes de reserva de suelo para vivienda sometida a algún régimen de protección pública

Francisca Picazo-Ruiz

Jefa Servicio Subdirección General Políticas Urbanas Ministerio de Transportes, Movilidad y Agenda Urbana

RESUMEN: El presente artículo aborda el estudio específico de los porcentajes que la legislación española establece en orden a exigir que una parte del suelo se reserve para la construcción de viviendas que cuenten con algún tipo de protección pública, es decir, aquellas que presentan un régimen jurídico mucho más condicionado que el de la vivienda libre y cuyo acceso se facilita a la población que presenta una situación económica más desfavorecida. El derecho constitucional de todos los españoles a disfrutar de una vivienda digna y adecuada establecido en el artículo 47, justifica el establecimiento de instituciones, como la de estas reservas, que conduzcan a su consecución efectiva.

PALABRAS CLAVE: Reserva de suelo; Vivienda protegida; Patrimonio público de suelo.

\section{Land reservation percentages for housing subject to some public protection regime: a comparative study}

ABSTRACT: This article addresses the specific study of the percentages that Spanish legislation establishes in order to require that a part of the land be reserved for the construction of houses that have some type of public protection, that is, those that present a legal regime very more conditioned than that of free housing and whose access is facilitated to the population with a more disadvantaged economic situation. The constitutional right of all Spanish people to enjoy a decent and adequate housing established in Article 47, justifies the establishment of institutions - such as these reserves- that lead to its effective achievement.

KEYWORDS: Land reserve; Protected housing; Public land heritage.

Correo electrónico: fpicazo@mitma.es 


\section{El patrimonio municipal de suelo: un primer paso de la legislación en la vinculación del suelo con la vivienda protegida}

\begin{abstract}
I I objetivo esencial de este artículo es el análisis de los porcentajes que la legislación española establece para posibilitar que una parte del suelo se destine a la construcción de viviendas que cuenten con algún tipo de protección pública (en adelante VPP).

Podría decirse que el establecimiento y regulación de dichos porcentajes constituye una institución relativamente moderna en el urbanismo español, aunque la necesidad de que el suelo, de alguna manera, quede comprometido en la construcción de viviendas accesibles a la población menos favorecida, es una constante en la legislación española del suelo desde sus orígenes.
\end{abstract}

La primera ley de suelo, la Ley sobre el régimen del suelo y ordenación urbana de 12 de mayo de 1956, ya dejaba constancia de que los poderes públicos debían implicarse en la necesidad de destinar suelo a la construcción de vivienda protegida, de modo que, entre las funciones que el artículo 3.2 atribuía a la competencia urbanística estaba la de:

"regular el mercado de terrenos como garantía de la subordinación natural de los mismos a los fines de la edificación y de la vivienda económica y la de adquirir terrenos y construcciones para constituir patrimonios de suelo".

En esta línea, y con la finalidad de regular el mercado del suelo, se crearon los "patrimonios municipales del suelo" (en adelante PMS) ${ }^{1}$ que permitían a los ayuntamientos ceder terrenos a título gratuito o por precio inferior al coste, para destinarlos a fines culturales públicos o a la construcción de las llamadas viviendas ultraeconómicas. La reforma que se llevó a cabo con la Ley 19/1975, de 2 de mayo, impuso a los propietarios del suelo la obligación de ceder una parte de la edificabilidad con el fin de reforzar los citados PMS, lo que a la postre redundaría en la mejor consecución de sus objetivos, entre los que tenía - como se acaba de indicar- especial protagonismo la construcción de las citadas

\footnotetext{
1 "1. Los ayuntamientos de capitales de provincia, los de población superior a 50.000 habitantes, los que voluntariamente lo acuerden y los demás que señalare la Comisión Central de Urbanismo, constituirán su respectivo Patrimonio municipal del suelo.

2. Dicho Patrimonio tendrá por finalidad prevenir, encauzar
}

viviendas. El Real Decreto 1346/1976, de 9 de abril, por el que se aprobó el Texto Refundido de la Ley sobre el Régimen del Suelo y Ordenación Urbana, permitía a los ayuntamientos:

\section{"ceder terrenos del Patrimonio municipal del suelo para ser edificados o destinados, en general, a los fines previstos en el Plan de ordenación",}

pero en caso de que la cesión lo fuera a título gratuito o por precio inferior al de coste debían únicamente ser destinados para atender necesidades de viviendas de carácter social².

Igual vinculación entre estos suelos y la VPP se puede constatar en la legislación estatal posterior; así, la Ley 8/1990, de 25 de julio, sobre Reforma del Régimen Urbanístico y Valoraciones del Suelo, en su Exposición de Motivos se expresaba en los siguientes términos:

\begin{abstract}
"La potenciación de los patrimonios municipales de suelo no tiene un alcance meramente cuantitativo, sino también cualitativo, en cuanto al destino que a los mismos ha de darse. En efecto, en el momento que se decida su urbanización, los terrenos integrados en estos patrimonios quedan vinculados primordialmente a la construcción de viviendas de protección oficial u otras finalidades de interés social, pues no sería justo ni coherente con el contenido del artículo 47 de la Constitución que las Entidades locales utilizasen los terrenos de su propiedad con miras puramente lucrativas, contribuyendo a incrementar las tensiones especulativas en vez de atenuarlas."
\end{abstract}

Su artículo 98.3 fue literalmente reproducido por el Real Decreto Legislativo 1/1992, de 26 de junio, que aprobaría el Texto Refundido de la Ley sobre el Régimen del Suelo y Ordenación Urbana, en su artículo 280.1:

\begin{abstract}
"Los bienes del Patrimonio Municipal del Suelo, una vez incorporados al proceso de urbanización y edificación, deberán ser destinados a la construcción de viviendas sujetas a algún régimen de protección pública o a otros usos de interés social, de acuerdo con el planeamiento urbanístico."
\end{abstract}

La Ley $8 / 2007$, de 28 de mayo, de Suelo, enfatizaba más, con un "deberán", en la preferencia de destinar los bienes de los patrimonios públicos de suelo (en adelante PPS) a la construcción de VPP, si bien admitía que "podrán" tener

y desarrollar técnica y económicamente la expansión de las poblaciones, y se adscribirá a la gestión urbanística para la inmediata preparación y enajenación de solares edificables y reserva de terrenos de futura utilización." (Artículo 72 de la Ley de 1956).

2 Artículos 165 y 166 del Real Decreto 1346/1976. 
como destino también "otros usos de interés social" aunque es cierto que con los condicionantes que expresaba su artículo 34.1:

"Los bienes y recursos que integran necesariamente los patrimonios públicos de suelo en virtud de lo dispuesto en el apartado 1 del artículo anterior, deberán ser destinados a la construcción de viviendas sujetas a algún régimen de protección pública. Podrán ser destinados también a otros usos de interés social, de acuerdo con lo que dispongan los instrumentos de ordenación urbanística, sólo cuando así lo prevea la legislación en la materia especificando los fines admisibles, que serán urbanísticos o de protección o mejora de espacios naturales o de los bienes inmuebles del patrimonio cultural."

Posteriormente, la Ley $8 / 2013$, de 26 de junio, introdujo ciertas modificaciones a esta redacción que se reflejaron en el artículo 39.1 del entonces vigente Texto Refundido de la Ley de Suelo, aprobado por Real Decreto Legislativo $2 / 2008$, de 20 de junio, y que se mantienen en la redacción actual contenida en el Real Decreto Legislativo 7/2015, de 30 de octubre, por el que se aprueba el Texto Refundido de la Ley de Suelo y Rehabilitación Urbana (en adelante TRLSyRU), en concreto en el artículo 52.1 que establece lo siguiente:

"Los bienes y recursos que integran necesariamente los patrimonios públicos de suelo en virtud de lo dispuesto en el apartado 1 del artículo anterior, deberán ser destinados a la construcción de viviendas sujetas a algún régimen de protección pública, salvo lo dispuesto en el artículo 18.2 a). Podrán ser destinados también a otros usos de interés social, de acuerdo con lo que dispongan los instrumentos de ordenación urbanística, sólo cuando así lo prevea la legislación en la materia especificando los fines admisibles, que serán urbanísticos, de protección o mejora de espacios naturales o de los bienes inmuebles del patrimonio cultural, o de carácter socio-económico para atender las necesidades que requiera el carácter integrado de operaciones de regeneración urbana."

Como se observa, en la actualidad sigue considerándose prioritario o preferente destinar el PPS - al menos el que procede del rescate de plusvalías como resulta del artículo 18.1.b-a la construcción de VPP y sólo se "podrán" destinar a otros usos de interés social con ciertos condicionantes: que lo prevea la legislación en la materia, que se especifiquen los fines y que estos estén dentro de los enumerados en el precepto. No obstante, y a pesar del carácter residual que parecen presentar esos otros usos de interés social — cuya evolución legislativa ${ }^{3}$ se acaba de exponer- cierto es que resulta un camino considerablemente amplio al que fácilmente puede acudir la legislación autonómica para dispersar el destino de dichos patrimonios.

\section{La creación de reservas de suelo para construir viviendas protegidas}

La aprobación de la Constitución Española en 1978 y, más en concreto, su artículo 47 con el mensaje claro para todos los poderes públicos de que deben promover las condiciones necesarias que permitan hacer efectivo el derecho de todos los españoles a disfrutar de una vivienda digna y adecuada, justifican, sin duda, la aparición de mecanismos o instituciones que coadyuven a su cumplimiento.

A partir de ese momento, los poderes públicos desarrollarán actuaciones que terminarán provocando la aparición de una nueva obligación urbanística: la de reservar un porcentaje de suelo para construir VPP. En este sentido, junto con la obligación de constituir los PPS, se abre otro camino en la obtención de vivienda asequible para la población más vulnerable. Esta nueva vía, como señala MAGUREGUI SALAS (2018):

"no viene sino a ratificar el fracaso de las políticas públicas de intervención en el mercado inmobiliario por parte de los entes locales - a través de los patrimonios municipales del suelo- puesto que dicha provisión de vivienda asequible era precisamente uno de sus objetivos".

\subsection{Los inicios}

\subsubsection{Los planes generales y la jurisprudencia}

En atención al mandato constitucional antes referido, serían los planes generales de ordenación urbanística de los años 80 los que empezarían a tomar la decisión de que parte del suelo residencial se pudiera destinar especialmente a la construcción de VPP.

Supuesto conocido, por la litigiosidad que provocó, fue el del acuerdo de la Comisión de Planeamiento y Coordinación del Área Metropolitana de Madrid de fecha 20 de octubre de 1981, que aprobó el

\footnotetext{
${ }^{3}$ LÓPEZ VIÑA (2019).
} 
Texto definitivo de las Directrices de Planeamiento Territorial y Urbanístico para la revisión del Plan General de Ordenación Urbana del Área Metropolitana de Madrid. Entre dichas directrices la 17 disponía que:

"Los Planes Generales introducirán las determinaciones necesarias para favorecer en el nuevo desarrollo residencial la mayor diversidad posible de tipologías edificatorias y de tamaños de viviendas y en especial de viviendas de protección oficial, a efectos de evitar la segregación social y acomodar la oferta a los deseos de la población."

Esta directriz 17 fue anulada por la Sentencia de la Audiencia Territorial de Madrid de 11 de enero de 1985 y la posterior Sentencia del Tribunal Supremo de 1 de junio de 1987 la confirmaría en los siguientes términos:

"[...] lo que en modo alguno autoriza la Ley del Suelo es que los Planes, una vez asignado el uso, (en este caso de viviendas), impongan también un régimen especial para la construcción, como es el de viviendas de protección oficial, que implica limitaciones a la propiedad que, en el sistema de la Ley del Suelo, carecen de los necesarios mecanismos de compensación, por la sencilla razón de que dicho régimen es un régimen de fomento, de elección voluntaria, que la Administración trata de fomentar mediante el otorgamiento de ventajas no estrictamente urbanísticas, sino de financiación y fiscales. Por lo tanto, en la medida en que la directriz número 17 se interprete como autorizando a los Planes a vincular suelo al régimen de viviendas de protección oficial, es una directriz ilegal, por violar el sistema general establecido en la Ley del Suelo."

En esta línea, la Sentencia del Tribunal Supremo de 16 de octubre de 1990, confirmando la de la Audiencia Territorial de Sevilla de 12 de septiembre de 1988, exponía que:

"[...] la finalidad perseguida por el planeamiento cuando destina parcelas a la construcción de viviendas de protección oficial es perfectamente plausible, viene declarando que el sentido de nuestro ordenamiento jurídico en materia de dichas viviendas discurre por el cauce del fomento y no por el de la técnica urbanística de la vinculación del suelo a un cierto destino - sentencias de 1 de junio de 1987, 23 de octubre de 1989-, de suerte que el planeamiento, en cuanto norma dictada por la Administración, no es instrumento apto para imponer aquel destino, al faltarle la base legal necesaria con arreglo a lo dispuesto en el art. 33.2 de la Constitución."

En resumen, la jurisprudencia resultó unánime (se pueden citar otras sentencias posteriores como las de 21 de mayo de 1991, 29 de enero de 1992, 5 de febrero de 1992, 8 de julio de
1992, 29 de marzo de 1999 ...) al entender que ese modo de vincular el suelo en realidad no era sino una verdadera limitación al derecho de propiedad y esas limitaciones sólo eran admisibles amparadas en una previsión legal que lo permitiera y, en aquel entonces, el Texto Refundido de 1976, no ofrecía la cobertura legal necesaria para que los planes pudieran calificar suelo destinado a construir VPP.

\subsubsection{La reacción estatal}

El legislador estatal aprobó poco después la Ley 8/1990, de 25 de julio, sobre Reforma del Régimen Urbanístico y Valoraciones del Suelo, posiblemente la ley más innovadora y rupturista de cuantas se han promulgado en relación con el urbanismo español; una ley que no ignoró la imposibilidad del planeamiento para adscribir suelo a VPP y que le procuró la cobertura legal que necesitaba.

En aquel momento, y así lo indicaba su preámbulo, se padecía un fuerte incremento del precio del suelo y, por ende, de la vivienda,

"[...] motivo de seria preocupación para los poderes públicos, que deben promover las condiciones necesarias para conseguir una utilización del suelo de acuerdo con el interés general e impedir la especulación"

\section{y, por otra parte, reconocía que:}

"el ordenamiento jurídico vigente (básicamente, la Ley sobre Régimen del Suelo y Ordenación Urbana, texto refundido aprobado por Real Decreto 1346/1976, de 9 de abril) se ha revelado insuficiente por la excesiva permisividad de que disfrutan los propietarios del suelo, que son los llamados en primer término a realizar las tareas de urbanización y edificación, y por la rigidez, cuando no ausencia, de los instrumentos de que dispone la Administración para hacer frente al incumplimiento por los particulares de los plazos señalados para la ejecución de dichas tareas, para incrementar los patrimonios públicos de suelo en medida suficiente para incidir en la regulación del mercado inmobiliario o para adscribir superficies de suelo urbanizable a la construcción de viviendas de protección oficial".

Su artículo 35.3 contemplaba expresamente la posibilidad de que el planeamiento urbanístico afectase terrenos a la construcción de VPP en los siguientes términos:

"Si el planeamiento general calificara terrenos con destinos a la construcción de viviendas de protección oficial u otro régimen de protección pública, 
considerará esta calificación como un uso específico, asignándosele el coeficiente de ponderación que, justificadamente y en coordinación con los criterios de valoración catastral, exprese su valor en relación con el característico del área de reparto en que quede incluido."

Se trataba de una solución asociada a la configuración de la VPP como tipología de uso, que permitía calificar terrenos con este destino (MúÑoz PÉREZ, 2018). En opinión de MERELO ABELA (1991) la consideración de esta afectación como calificación urbanística o uso específico era, ciertamente, algo artificial, pues en rigor, no se trataba sino de un régimen constructivo con una específica financiación que se traducía en limitaciones en el precio de venta o arrendamiento de las viviendas acogidas al mismo.

Lo cierto es que esa expresión condicional del artículo 35.3 serviría para que el planeamiento pudiera efectuar la calificación de terrenos para VPP que la jurisprudencia le había negado años antes. En definitiva, la ley, si quiera sea indirectamente, admitía entre las funciones del planeamiento la de efectuar dicha calificación.

El posterior Real Decreto Legislativo 1/1992, de 26 de junio, que aprobó el Texto Refundido de la Ley sobre el Régimen del Suelo y Ordenación Urbana, por un lado, en su art. 3.2.h) recogía entre las facultades de la competencia urbanística la de "calificar terrenos para construcción de viviendas sujetas a algún régimen de protección pública" $y$, por otro lado, reproducía literalmente en su artículo 98.3 el texto del artículo 35.3 de la Ley $8 / 90$ antes citado.

Pero el artículo 98.3 no se libraría de la debacle que para el Real Decreto Legislativo 1/1992 supuso la controvertida Sentencia del Tribunal Constitucional 61/1997, de 20 de marzo. En efecto - señalaba su fundamento jurídico 24 :

"[...] la conexión del sector vivienda y la actividad promocional con la política económica general puede quedar suficientemente acreditada «en razón de la incidencia que el impulso de la construcción tiene como factor económico y, en especial, como instrumento generador de empleo» [...]", ahora bien [...] el objeto directo del art. 98.3 TRLS es la regulación de uno de los elementos del aprovechamiento tipo, sin que su clara conexión con la promoción indirecta y mediata de viviendas de protección pública pueda tener la virtualidad de atraer hacia el art. 149.1.13. ${ }^{\circ} \mathrm{CE}$ la regulación con carácter básico de la materia, concluyendo que el art. 98.3 TRLS establece determinadas prescripciones estrictamente urbanísticas (calificación de uso específico; asignación de un coeficiente de ponderación y sus reglas), con lo que invade la competencia urbanística que corresponde a las Comunidades Autónomas".

\subsubsection{Las primeras legislaciones autonómicas}

Tras la Sentencia del Tribunal Constitucional y las lagunas provocadas por la misma en la legislación vigente, las Comunidades Autónomas (en adelante CC. AA.) tuvieron que ponerse de inmediato a decidir sobre su legislación en materia de urbanismo ${ }^{4}$.

Un pequeño y avanzado grupo de las mismas ya habían iniciado su periplo legislativo en el urbanismo y algunas optaron por empezar a regular la materia objeto de este artículo con mayor detalle, incorporando incluso porcentajes concretos de reserva ${ }^{5}$. Así lo hicieron por orden cronológico:

A. Navarra. Fue la pionera con la Ley Foral $7 / 1989$, de 8 de junio, de medias de intervención en materia de suelo y vivienda, que estableció la necesidad de incluir determinaciones para asegurar que, como mínimo, el $\mathbf{1 5 \%}$ del suelo residencial o de su capacidad se destinase a la construcción de vivienda de protección oficial (en adelante VPO), aunque sólo sería aplicable a los municipios de más de 2.000 habitantes. La posterior Ley Foral 10/1994, de 4 de julio de Ordenación del Territorio y Urbanismo, aplicaría ese porcentaje sobre la nueva capacidad residencial prevista.

B. País Vasco. La legislación vasca, que se viene caracterizando por establecer reservas con porcentajes sustancialmente elevados si se compara con la media de las demás CC. AA., ya inicialmente con la Ley 17/1994, de 30 de junio, aplicaba a los municipios de más de 7.000 habitantes la reserva para VPP constituida por el suelo necesario para materializar el aprovechamiento mínimo del $\mathbf{2 0} \%$ del total residencial en suelo urbano (en adelante SU) y del $65 \%$ en suelo urbanizable (en adelante SUBLE) programado.

C. Madrid. La Ley 9/1995, de 28 de marzo, de Medidas de Política Territorial, Suelo y

${ }^{4}$ Beato Espejo (1999).

${ }^{5}$ BLANCO González (2010) pág. 71 a 73. 
Urbanismo, establecía con carácter general para los municipios de 25.000 o más habitantes, la obligación de reservar un $\mathbf{5 0 \%}$ del SUBLE destinado al uso residencial para construir VPP.

D. Galicia. La Ley 1/1997, de 24 de marzo de Suelo, reproduciendo el Texto Refundido estatal de 1992 contemplaba la necesidad de calificar terrenos para esta finalidad, pero no concretaba porcentaje de reserva alguna.

Como puede observarse, la heterogeneidad inicial era muy alta.

\subsection{La primera normativa estatal en establecer un porcentaje de reserva de suelo para vivienda protegida en todo el territorio nacional}

Aunque no todas las leyes autonómicas habían regulado las reservas de suelo para VPP, es cierto que el efecto contagio hacía sospechar su más que probable generalización, con el riesgo añadido de encontrarnos con regulaciones sustancialmente diferentes, tanto en cuanto a los porcentajes a aplicar — como se observa claramente en las legislaciones autonómicas antes citadas- como en cuanto a la forma de su cómputo (suelo, aprovechamiento, edificabilidad ...), o los suelos sobre los que se aplicaría, o el tamaño de los municipios por debajo del cual no sería exigible, etc.

\subsubsection{La Ley $8 / 2007$, de 28 de mayo, de Suelo}

Ante esta perspectiva el legislador estatal, al enfrentarse con lo que sería la nueva legislación en la materia, a saber, la Ley $8 / 2007$, de 28 de mayo, de Suelo, optó por incorporar una regulación general y básica en relación con las reservas para la construcción de VPP, que las legislaciones autonómicas podrían adaptar, respetando en todo caso el mínimo establecido.

Su exposición de motivos recogía la justificación competencial en los siguientes términos:

"Mención aparte merece la reserva de suelo residencial para la vivienda protegida porque, como ya se ha recordado, es la propia Constitución la que vincula la ordenación de los usos del suelo con la efectividad del derecho a la vivienda. A la vista de la senda extraordinariamente prolongada e intensa de expansión de nuestros mercados inmobiliarios, y en particular del residencial, parece hoy razonable encajar en el concepto material de las bases de la ordenación de la economía la garantía de una oferta mínima de suelo para vivienda asequible, por su incidencia directa sobre dichos mercados y su relevancia para las políticas de suelo y vivienda, sin que ello obste para que pueda ser adaptada por la legislación de las Comunidades Autónomas a su modelo urbanístico y sus diversas necesidades".

Se apoya, por tanto, en la competencia exclusiva que le otorga el art. 149.1.13 de la Constitución sobre las bases y coordinación de la planificación general de la actividad económica.

Su artículo 10.b) estableció una reserva mínima del $30 \%$ de la edificabilidad residencial en las actuaciones de urbanización, lo que suponía su aplicación tanto en los supuestos de nueva urbanización (que podrían identificarse, normalmente, con las actuaciones sistemáticas o integradas en SUBLE), como en los de reforma o renovación de la urbanización (serían las actuaciones sistemáticas o integradas en SU no consolidado -en adelante SUNC), por aplicación de las definiciones contenidas en el artículo 14.1.a) de la propia Ley, equivalente al artículo 7.1.a) del vigente TRLSyRU, que posteriormente se verá.

Completaba la regulación la disposición transitoria primera que imponía la reserva del artículo 10.b) a todos los cambios de ordenación iniciados tras su entrada en vigor y que concedía un año de plazo para que pudieran adaptarse aquellas leyes autonómicas que no tuvieran establecidas reservas iguales o superiores. A falta de dicha adaptación se les aplicaría la reserva del $30 \%$ con dos precisiones, una conteniendo supuestos de exención y otra sobre la compensación si se minoraba el porcentaje. Con la adaptación temporal necesaria, el texto de esta disposición coincide con el apartado 1 de la vigente disposición transitoria primera del TRLSyRU, que luego se reproducirá.

La Ley 8/2007 rápidamente se refundió con el Texto Refundido de 1992 convirtiéndose en el Real Decreto Legislativo 2/2008, de 20 de junio, por el que se aprobó el Texto Refundido de la Ley de Suelo, el cual -como no podía ser de otra manera al tratarse de una mera refundición de textos normativos - no introdujo ninguna novedad en el tema de las reservas. 


\subsubsection{La Ley $8 / 2013$, de 26 de junio, de rehabilitación, regeneración y renovación urbanas}

La situación de crisis económica que se padecería en los años posteriores hicieron que la Ley 8/2013, de 26 de junio, de rehabilitación, regeneración y renovación urbanas introdujera modificaciones en la regulación estatal de las reservas de suelo, modificaciones que literalmente se han trasladado al vigente TRLSyRU.

La Ley 8/2013 entendió necesario:

$\left.1^{\circ}\right)$ Por un lado, afinar más en la regulación y reajustar el porcentaje, diferenciando su cuantía en función de que la actuación de urbanización fuere nueva, tratándose de un suelo en situación de rural — según la nueva terminología empleada por la legislación estatal a partir de la Ley 8/2007-, o que el objetivo fuere reformar o renovar la urbanización de un suelo que ya estaba urbanizado en cuyo caso el porcentaje se vería reducido al $10 \%$.

Su Exposición de Motivos indicaba que uno de los objetivos que se perseguía con la reforma del Real Decreto Legislativo 2/2008 era el de superar la práctica identidad existente entre los suelos en situación de urbanizados y los suelos en situación rural, con destino a una operación de transformación urbanística. En esa línea señalaba que,

"[...] con la misma idea de flexibilizar, se incluye una modificación en la regla básica estatal que, desde el año 2007, ha tratado de garantizar una oferta mínima de suelo para vivienda asequible, exigiendo un 30 por ciento de la edificabilidad residencial prevista, en todos los suelos que fuesen objeto de actuaciones de urbanización. Esta regla, que se aplicaba por igual a los suelos urbanos y a los suelos urbanizables, se flexibiliza de manera específica cuando la actuación se realiza sobre suelo en situación de urbanizado, con la idea de asegurar en la mayor medida posible la ya complicada viabilidad de las operaciones de renovación urbana que impliquen una reurbanización del ámbito de actuación".

$2^{\circ}$ ) Por otro, establecer una regla excepcional y transitoria que permitiera a las CC. AA. dejar en suspenso durante un plazo máximo de cuatro años la aplicación de los porcentajes establecidos, con la idea de adecuarse a la nueva realidad de un mercado inmobiliaria en crisis. Una situación inmobiliaria en la que -como acertadamente indicaba su Exposición de Motivos-, por un lado, se había producido un acercamiento sustancial de los precios tanto de la vivienda libre como de la protegida (lo que le restaba toda competitividad a ésta), y por otro las familias vivían una difícil situación económica que les dificultaba tanto adquirir una vivienda, como acceder a una posible financiación. $Y$ continuaba señalando los efectos y la situación producida:

\begin{abstract}
"Todo ello provoca que hoy, en el stock de vivienda sin vender ya construida, se encuentren viviendas con protección pública, derivadas del cumplimiento de la mencionada reserva mínima estatal y que dicha reserva, por tanto, no sólo no esté coadyuvando al cumplimiento de los fines previstos, sino que esté rigidizando injustificadamente las operaciones que, sobre todo en el suelo urbano, pero también en gran medida en el suelo urbanizable, tienen posibilidades de realizarse, incluso en los momentos difíciles que atraviesa el sector inmobiliario."
\end{abstract}

Esta regla que permitía la suspensión de la reserva de suelo se terminó incorporando al vigente TRLSyRU como apartado 2 de la disposición transitoria primera que a continuación se verá.

\section{La legislación vigente sobre porcentajes de reserva de suelo destinados a vivienda sometida a algún régimen de protección pública}

\subsection{La legislación estatal}

El Real Decreto Legislativo 7/2015, de 30 de octubre, que aprueba el Texto Refundido de la Ley de Suelo y Rehabilitación Urbana, refunde el Real Decreto Legislativo 2/2008 y la Ley $8 / 2013$, y constituye la normativa estatal vigente en la materia, más en concreto su artículo 20.1.b) y la disposición transitoria primera cuyos textos se citan a continuación.

El artículo 20.1.b) establece para las Administraciones competentes en materia de ordenación territorial y urbanística la siguiente obligación:

"b) Destinar suelo adecuado y suficiente para usos productivos y para uso residencial, con reserva en todo caso de una parte proporcionada a vivienda sujeta a un régimen de protección pública que, al menos, permita establecer su precio máximo en venta, alquiler $u$ otras formas de acceso a la vivienda, como el derecho de superficie o la concesión administrativa. 
Esta reserva será determinada por la legislación sobre ordenación territorial y urbanística o, de conformidad con ella, por los instrumentos de ordenación, garantizará una distribución de su localización respetuosa con el principio de cohesión social y comprenderá, como mínimo, los terrenos necesarios para realizar el 30 por ciento de la edificabilidad residencial prevista por la ordenación urbanística en el suelo rural que vaya a ser incluido en actuaciones de nueva urbanización y el 10 por ciento en el suelo urbanizado que deba someterse a actuaciones de reforma o renovación de la urbanización.

No obstante, dicha legislación podrá también fijar o permitir excepcionalmente una reserva inferior o eximirlas para determinados Municipios o actuaciones, siempre que, cuando se trate de actuaciones de nueva urbanización, se garantice en el instrumento de ordenación el cumplimiento íntegro de la reserva dentro de su ámbito territorial de aplicación y una distribución de su localización respetuosa con el principio de cohesión social."

A efectos de la aplicación de los porcentajes antes citados, conviene recordar el artículo 7.1.a) que define, a efectos de la propia ley, lo que se entiende por actuaciones de urbanización, distinguiendo entre:

“1) Las de nueva urbanización, que suponen el paso de un ámbito de suelo de la situación de suelo rural a la de urbanizado para crear, junto con las correspondientes infraestructuras y dotaciones públicas, una o más parcelas aptas para la edificación o uso independiente y conectadas funcionalmente con la red de los servicios exigidos por la ordenación territorial y urbanística.

2) Las que tengan por objeto reformar o renovar la urbanización de un ámbito de suelo urbanizado, en los mismos términos establecidos en el párrafo anterior."

Teniendo en cuenta que, desde la Ley de Suelo de 2007, el legislador estatal ha optado por prescindir de la técnica urbanística de la clasificación del suelo y se refiere sólo a la situación real en la que se encuentren los terrenos, hay que concluir que dentro de las actuaciones de nueva urbanización sólo habrá suelos en situación de rural, es decir, los que el plan clasifica como urbanizables; en este caso la reserva mínima será del 30 por ciento. En el apartado 2 se trataría del suelo urbanizado, que en terminología urbanística se correspondería con el SUNC y que quedaría sometido al mínimo del 10 por ciento de reserva. Mínimo aplicable en todos los supuestos en que, de facto, se den los presupuestos establecidos por la legislación estatal, aunque la legislación autonómica no haga mención a reserva alguna, lo que sucede claramente en alguna normativa autonómica (Asturias, Cantabria, La Rioja, Madrid).

La disposición transitoria primera establece un régimen transitorio en la materia, cuyo apartado 2 contiene la regla temporal y excepcional que, como se ha comentado, introdujo la Ley 8/2013, que dice lo siguiente:

"1. Sin perjuicio de lo dispuesto en el apartado siguiente, la reserva para vivienda protegida exigida en la letra b) del apartado primero del artículo 20 de esta ley se aplicará a todos los cambios de ordenación cuyo procedimiento de aprobación se inicie con posterioridad a la entrada en vigor de la Ley $8 / 2007$, de 28 de mayo, de Suelo [1 de julio de 2007], en la forma dispuesta por la legislación sobre ordenación territorial y urbanística. En aquellos casos en que las comunidades autónomas no hubieren establecido reservas iguales o superiores a la que se establece en la letra b) del apartado primero del artículo 20 de esta ley, desde el 1 de julio de 2008 y hasta su adaptación a la misma, será directamente aplicable la reserva del 30 por ciento prevista en esta ley, con las siguientes precisiones:

A. Están exentos de su aplicación los instrumentos de ordenación de los municipios de menos de 10.000 habitantes en los que, en los 2 últimos años anteriores al del inicio de su procedimiento de aprobación, se hayan autorizado edificaciones residenciales para menos de 5 viviendas por cada 1.000 habitantes y año, siempre y cuando dichos instrumentos no ordenen actuaciones residenciales para más de 100 nuevas viviendas; así como los que tengan por objeto actuaciones de reforma o mejora de la urbanización existente en las que el uso residencial no alcance las 200 viviendas.

B. Los instrumentos de ordenación pueden compensar motivadamente minoraciones del porcentaje en las actuaciones de nueva urbanización no dirigidas a atender la demanda de primera residencia prevista por ellos con incrementos en otras de la misma categoría de suelo.

2. No obstante lo dispuesto en el apartado anterior, durante un plazo máximo de cuatro años a contar desde la entrada en vigor de la Ley 8/2013, de 26 de junio, de rehabilitación, regeneración y renovación urbanas [28.junio.2013], las comunidades autónomas podrán dejar en suspenso la aplicación de lo dispuesto en la letra b) del apartado primero del artículo 20 de esta ley, determinando el período de suspensión y los instrumentos de ordenación a que afecte, siempre que se cumplan, como mínimo, los siguientes requisitos: 
A. Que los citados instrumentos justifiquen la existencia de un porcentaje de vivienda protegida ya construida y sin vender en el Municipio, superior al 15 por ciento de las viviendas protegidas previstas o resultantes del planeamiento vigente y una evidente desproporción entre la reserva legalmente exigible y la demanda real con posibilidad de acceder a dichas viviendas.

B. Que dichos instrumentos de ordenación no hayan sido aprobados definitivamente antes de la entrada en vigor de esta ley o que, en el caso de haber sido aprobados, no cuenten aún con la aprobación definitiva del proyecto o proyectos de equidistribución necesarios."

El carácter temporal y meramente transitorio de la regla introducida por la Ley $8 / 2013$, hace que en la actualidad el apartado 2 de la disposición transitoria primera que la contiene ya no sea de aplicación.

Resulta de interés advertir como, a partir de la Ley de Suelo de 2007, las reservas para VPP se ligan a la necesidad de que su distribución sea respetuosa con el principio de cohesión socia/ ${ }^{6}$, con el fin de no rememorar la marginación social que llevaron implícitas las construcciones que décadas atrás se habían hecho, concentrado, a modo de guetos, grandes barriadas de VPP, con viviendas que acogieron una población inicial mayoritariamente proveniente del mundo rural. Por tanto, la legislación autonómica deberá tener en cuenta la aplicación de este principio, lo que limita su capacidad de reducir las viviendas de este tipo en determinados ámbitos con la finalidad de agruparlas extendiendo la superficie porcentual inicialmente prevista en otros.

Por último, conviene recordar la vigente disposición final segunda, sobre el título competencial y ámbito de aplicación, que en su apartado 1 reconoce que tanto el artículo 20 como la disposición transitoria primera forman parte de los preceptos dictados en virtud de la competencia exclusiva del Estado para regular las condiciones básicas que garanticen la igualdad en el ejercicio de los derechos y el cumplimiento de los deberes constitucionales, y, más en concreto, como ya especificara la Exposición de Motivos de la Ley de 2007, para establecer las bases y coordinación de la planificación general de la actividad económica.

En relación con los territorios de Ceuta y Melilla, reconociendo que son Ciudades Autónomas y que carecen de potestad legislativa, el Estado les permite que puedan ejercer, a través de su planeamiento, las potestades que las CC. AA. tienen que desarrollar mediante ley. En este sentido el apartado 8 de la disposición final segunda en relación con estas Ciudades precisa en la letra a) que:

"La potestad que la letra b) del apartado primero del artículo 20 reconoce a la ley para reducir el porcentaje de reserva de vivienda sometida a algún régimen de protección pública y la de determinar los posibles destinos del patrimonio público del suelo, de entre los previstos en el apartado 1 del artículo 34, podrán ser ejercidas directamente en el plan general."

\subsection{La legislación autonómica}

\subsubsection{Cuadro comparativo}

La vigente legislación autonómica sobre la materia se ha condensado en el cuadro que a continuación se expone. En él se contienen simplemente las referencias a las leyes y los preceptos específicos que en cada caso contienen dicha regulación por si se desea ver en detalle su redacción literal. No se reproducen sus textos por considerarlo innecesario y excesivamente prolijo.

\footnotetext{
${ }^{6}$ Ley de Suelo y gobiernos locales (2007).
} 


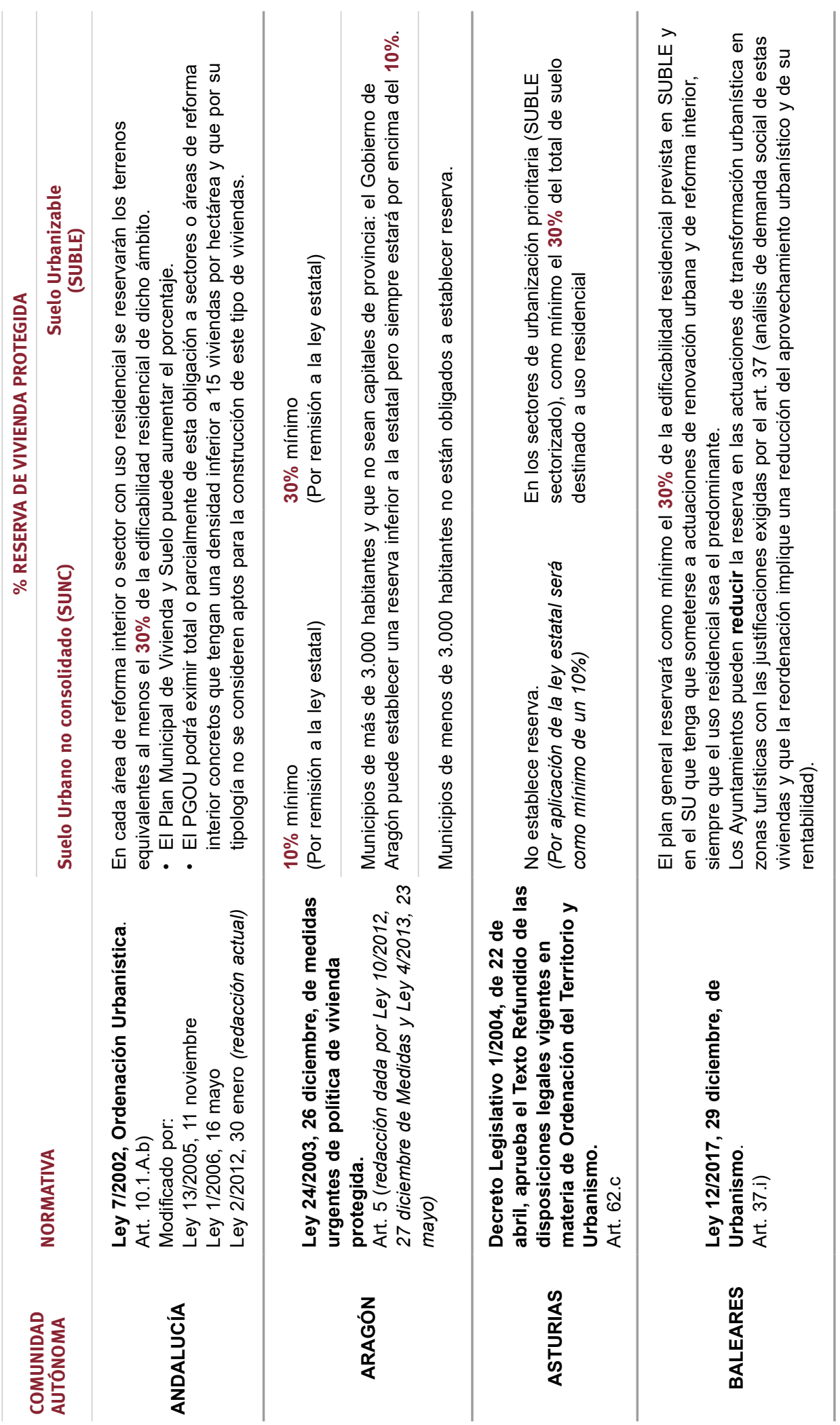




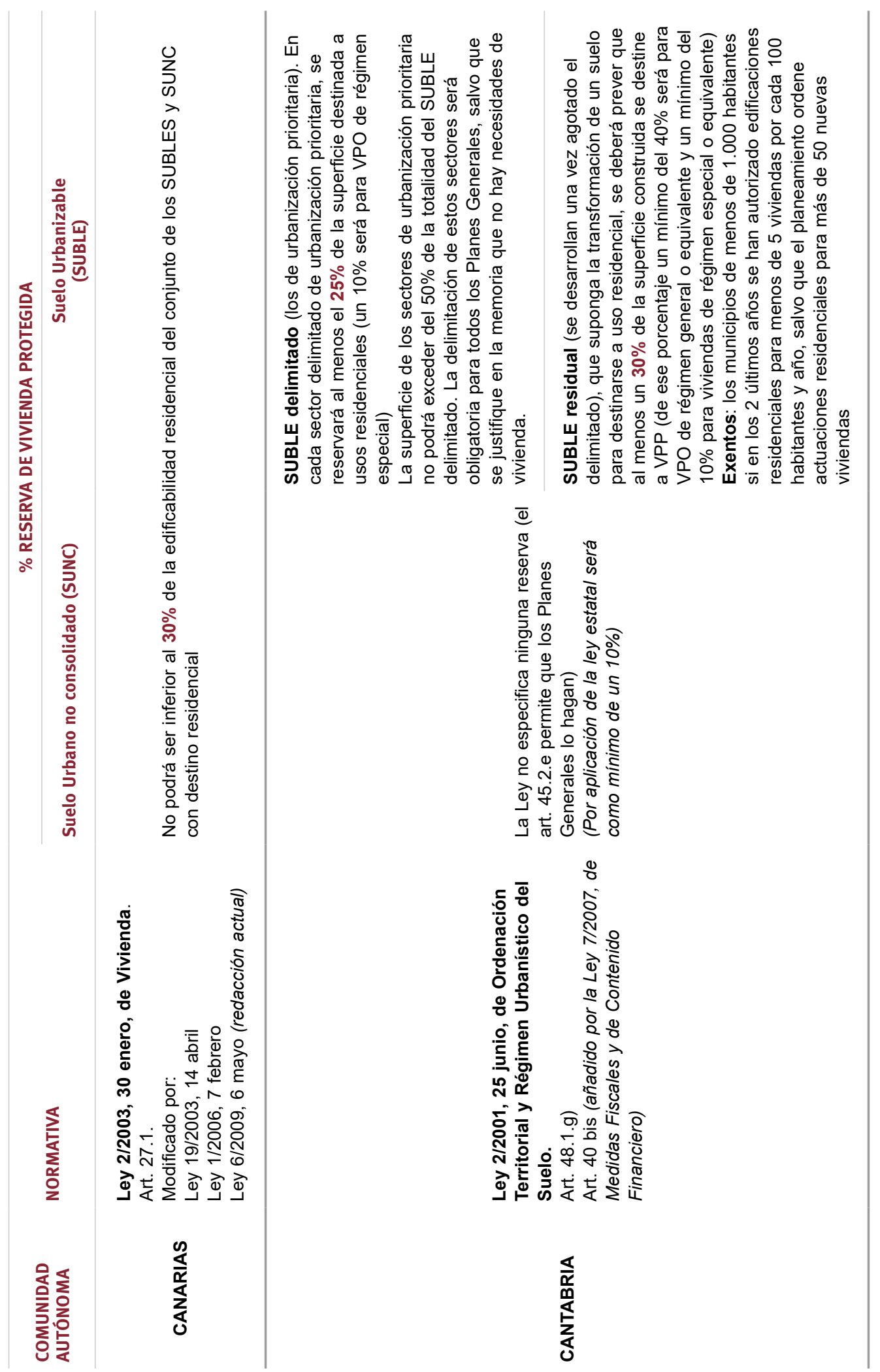



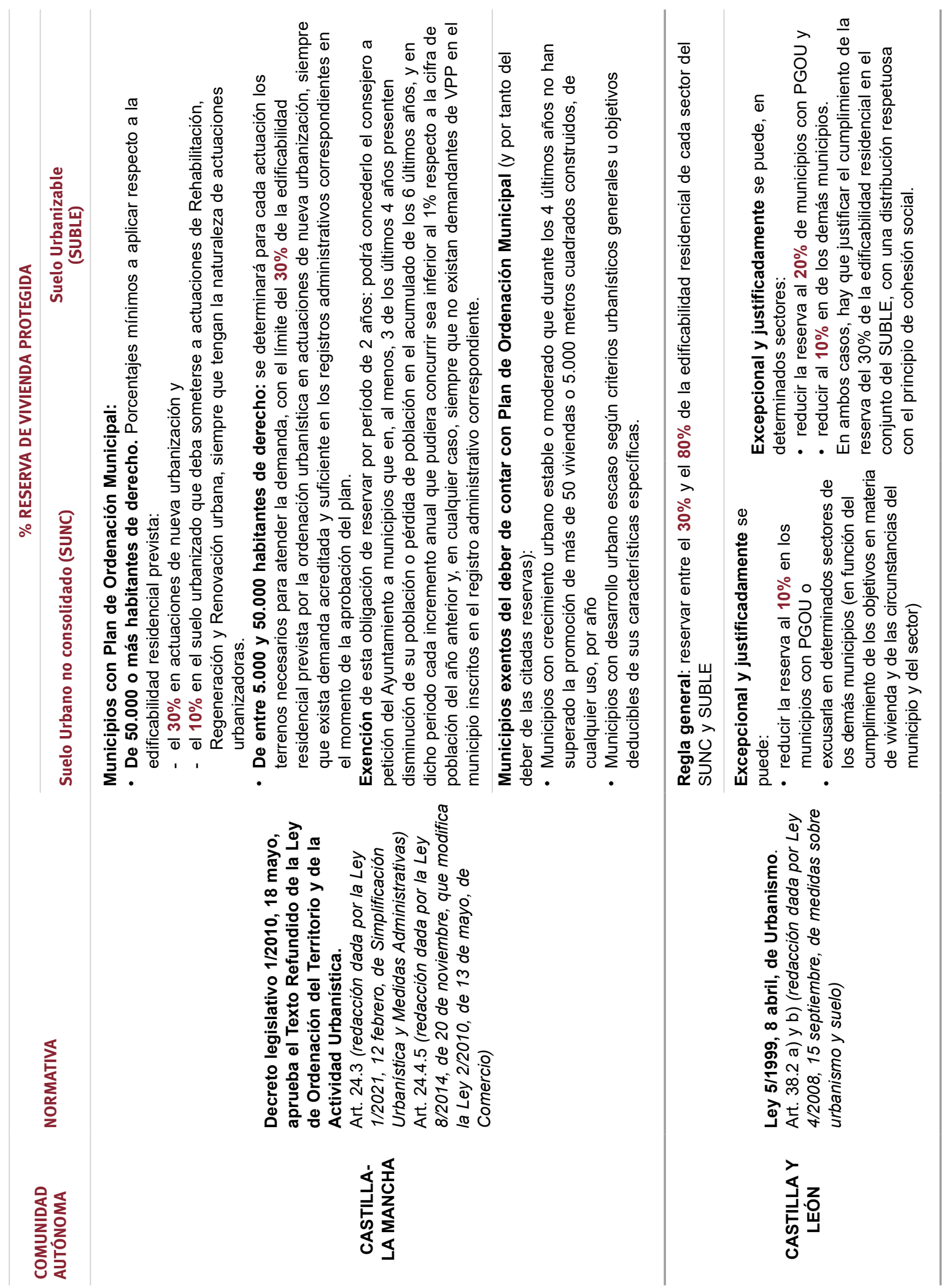


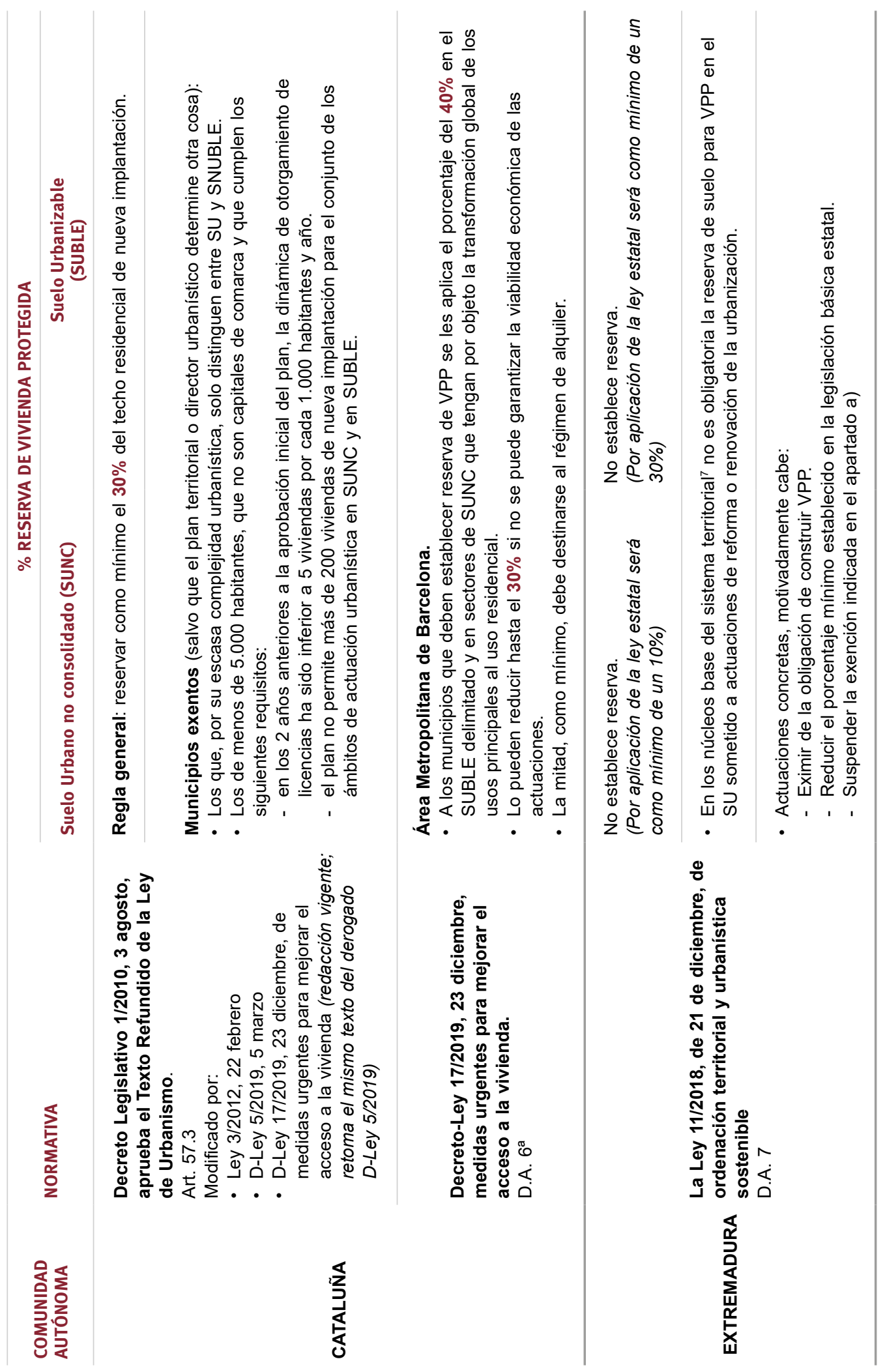




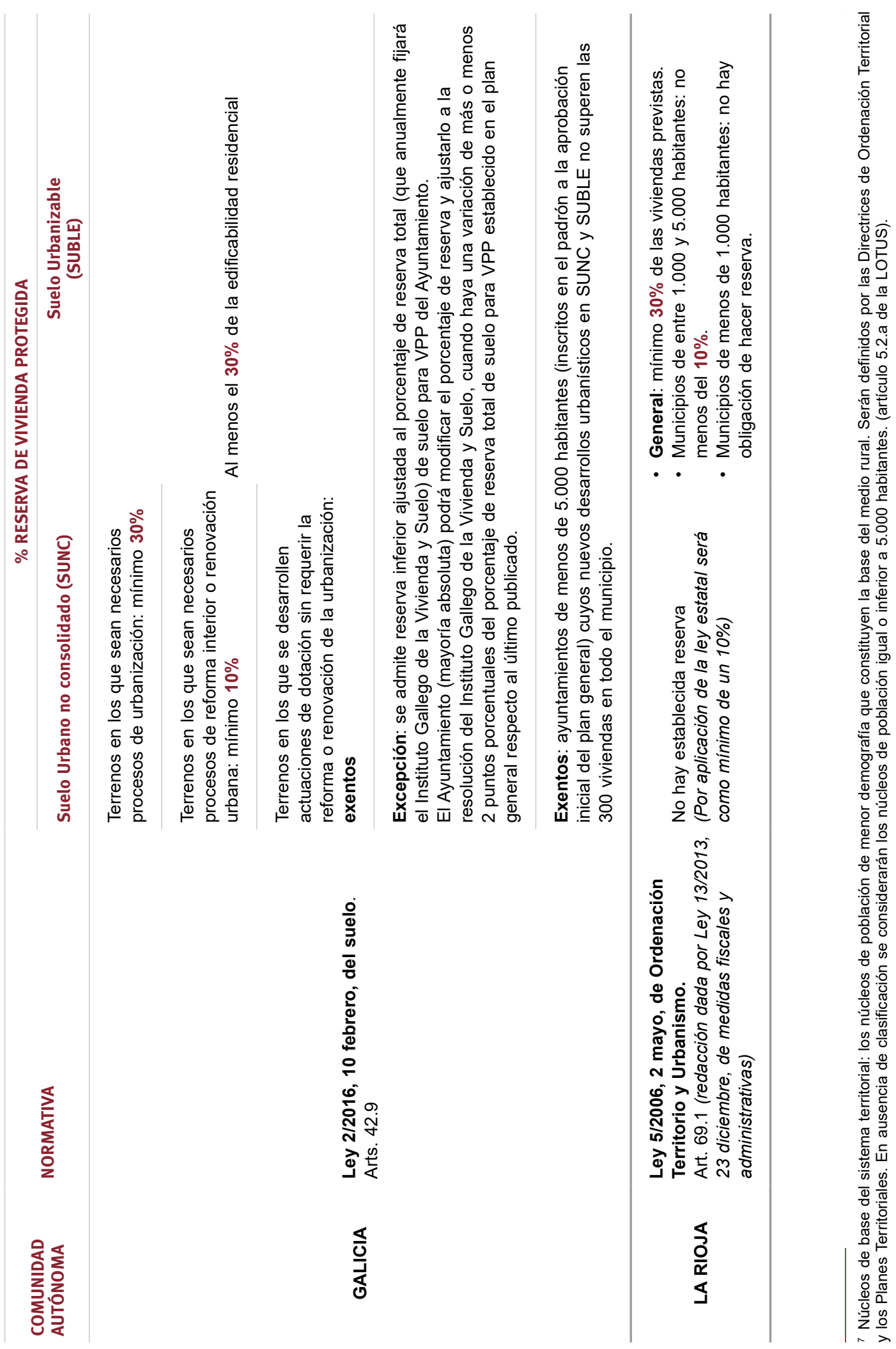




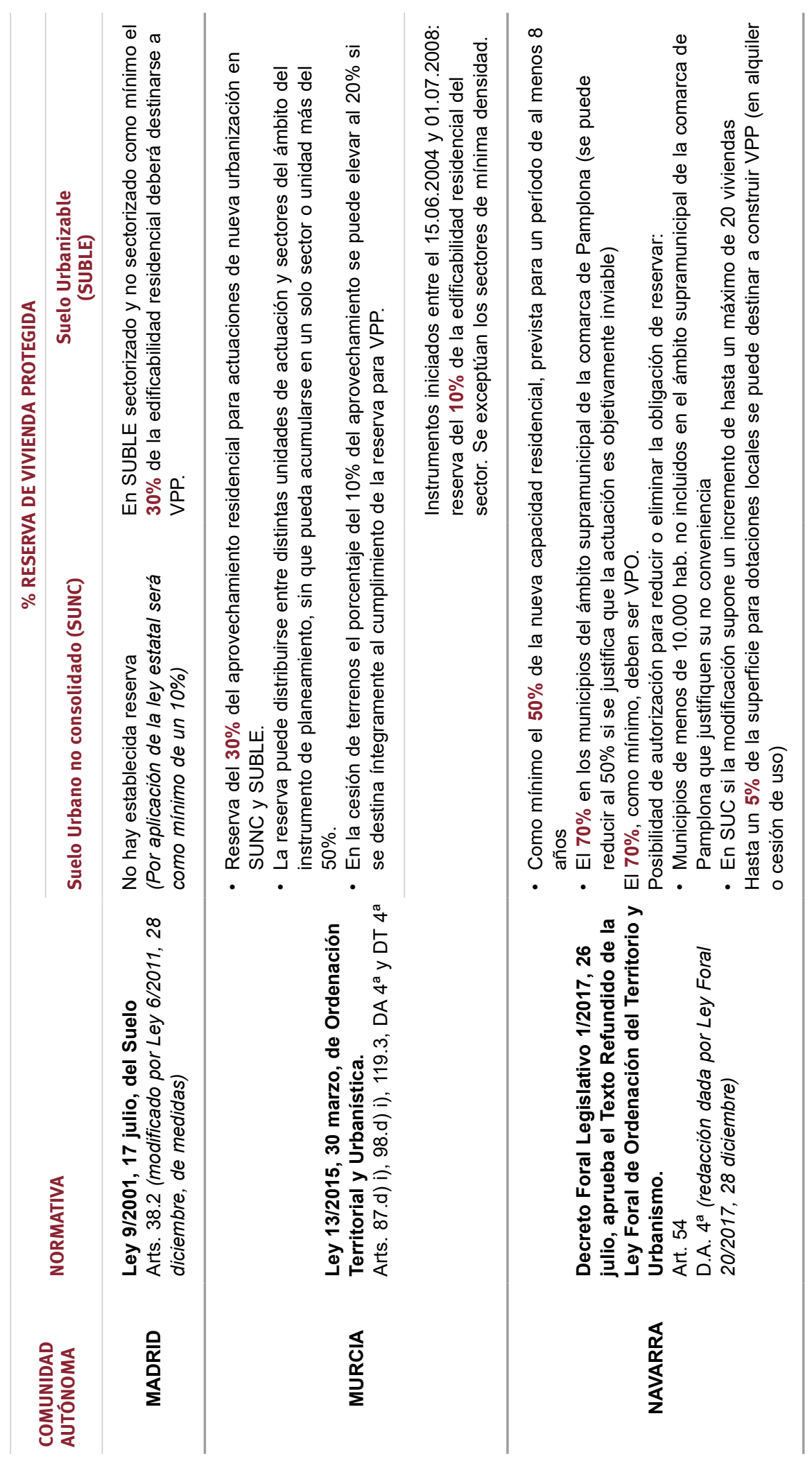




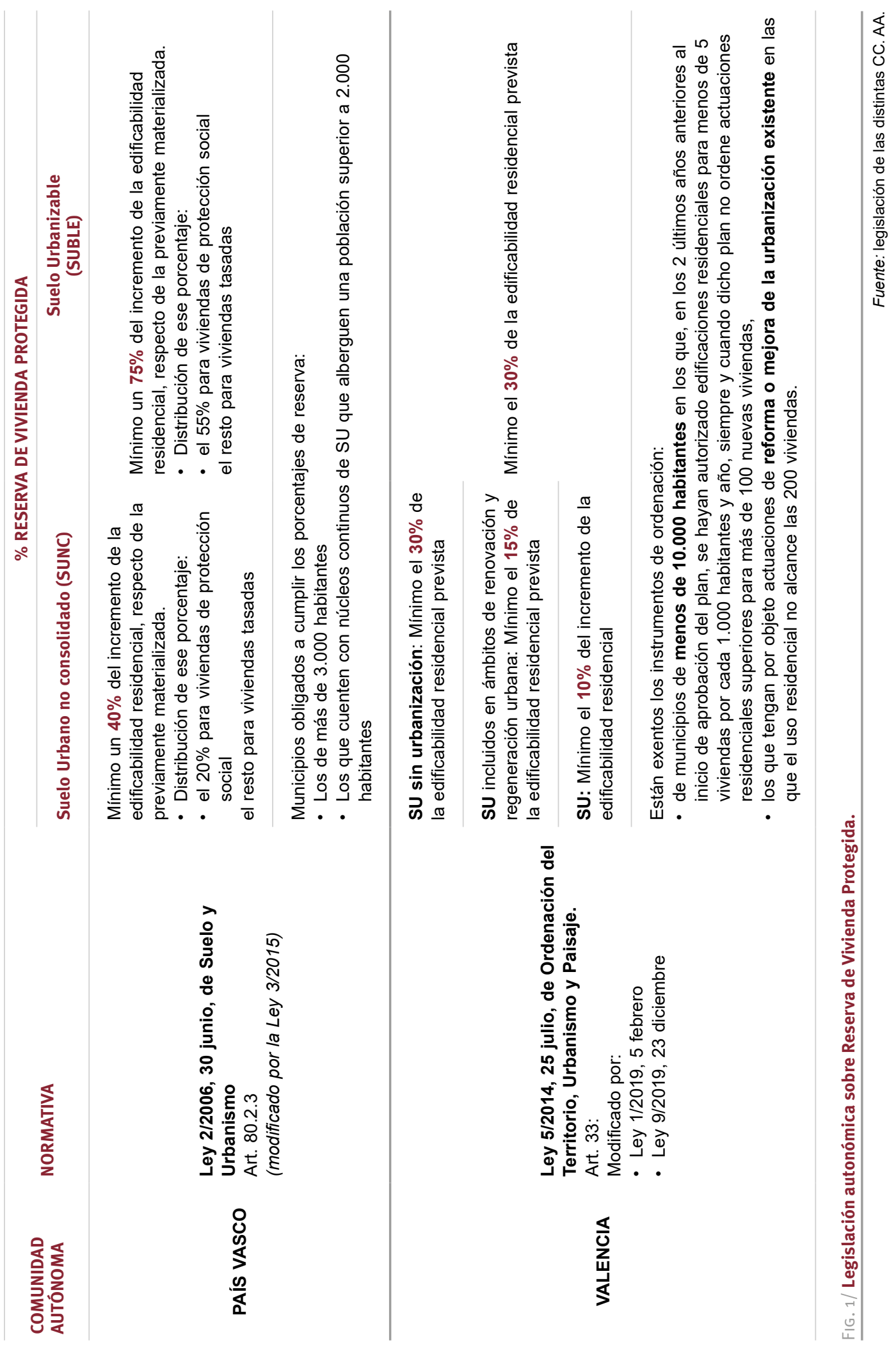




\subsubsection{Análisis esquemático del estudio comparado}

El régimen de reserva de VPP establecido por el Estado en el TRLSyRU, que deberá ser respetado por la legislación autonómica, es el siguiente:

\section{A. Regla general}

- Es obligatorio establecer un porcentaje de reserva para construir VPP.

- El porcentaje se aplicará sólo sobre la edificabilidad residencial, se excluyen por tanto del cómputo el resto de los usos. Si la legislación autonómica estableciese otro criterio para la reserva (de suelo, de aprovechamiento ...), habrán de realizarse las operaciones necesarias para convertirlo a dicha edificabilidad a fin de comprobar que cumplen con el porcentaje mínimo de edificabilidad residencial establecido. Como se observa en el cuadro que se adjunta a continuación, la mayoría de las CC. AA. refieren sus reservas a la edificabilidad residencial, siguiendo el criterio de la ley estatal.

\begin{tabular}{|c|c|}
\hline $\begin{array}{l}\text { Reserva de } \\
\text { edificabilidad } \\
\text { residencial }\end{array}$ & $\begin{array}{l}\text { ESTADO, Andalucia, Aragón, } \\
\text { Baleares, Canarias, } \\
\text { Cantabria, Castilla-La } \\
\text { Mancha, Castilla y León, } \\
\text { Cataluña (techo residencial) } \\
\text { Extremadura, Galicia, Madrid, } \\
\text { Navarra (nueva capacidad } \\
\text { residencial), País Vasco } \\
\text { (incremento de la } \\
\text { edificabilidad), Valencia }\end{array}$ \\
\hline $\begin{array}{l}\text { Reserva de suelo } \\
\text { residencial }\end{array}$ & Asturias \\
\hline $\begin{array}{l}\text { Reserva de } \\
\text { aprovechamiento } \\
\text { residencial }\end{array}$ & Murcia \\
\hline $\begin{array}{l}\text { Reserva de } \\
\text { viviendas }\end{array}$ & La Rioja \\
\hline
\end{tabular}

FIG. 2/ Cuadro resumen de los tipos de reserva.

Fuente: elaboración de la autora.

- El porcentaje mínimo que debe establecer la legislación autonómica será el siguiente:

- $\quad . .$. el $\mathbf{3 0} \%$ en el suelo rural incluido en actuaciones de nueva urbanización.

\footnotetext{
${ }^{8}$ Palmero Iglesias, L. (2018) pág.14.
}

- $\quad$... el $10 \%$ en el suelo urbanizado sometido a actuaciones de reforma o renovación de la urbanización.

- Si las legislaciones autonómicas estableciesen, en los supuestos de hecho citados, un porcentaje inferior o simplemente no contemplasen porcentaje alguno, serán de aplicación los porcentajes mínimos estatales.

\section{B. Excepción}

No obstante, lo anterior, las leyes autonómicas pueden establecer una reserva inferior o incluso su supresión en ciertos:

- Municipios (se entiende que serían los de escasa población ${ }^{8}$ o dinámica urbanística).

- Actuaciones (con singularidades tales como que se trate de urbanizaciones de baja densidad o que estén ubicadas en determinadas zonas de municipios turísticos, etc) ${ }^{9}$.

Conviene recordar que si se tratase de actuaciones de nueva urbanización deberá garantizarse el cumplimiento íntegro de la reserva dentro del ámbito territorial del plan y el respeto al principio de cohesión social en su distribución.

Es indudable que el legislador estatal, consciente de su realidad competencial, con los supuestos de excepción ofrece a la legislación autonómica un amplio margen de adaptación de la reserva a sus propias singularidades, que pueden llegar incluso a su supresión en estos casos excepcionales que requerirán justificación.

En general, las CC. AA. mantienen sus porcentajes en los márgenes que el legislador estatal fija como mínimos, lo que permite una cierta homogenización normativa.

Navarra y País Vasco son las únicas CC. AA. que saltan con holgura - como ya es tradicional en relación con este tema- los mínimos estatales.

Con el fin de ampliar o matizar la información autonómica contenida en el cuadro principal, se exponen a continuación aspectos de interés de algunas legislaciones autonómicas.

En Asturias el artículo 62.c) de su Decreto Legislativo 1/2004 sólo establece la reserva en

\footnotetext{
${ }^{9}$ Ley de Suelo y gobiernos locales (2007) pág. 43.
} 
el SUBLE sectorizado de urbanización prioritaria que, según su letra b), "son las áreas previstas para eliminar los déficit comprobados de vivienda, suelo industrial y equipamientos comunitarios". Por tanto, la ley urbanística no regula la reserva ni en los SUBLES no prioritarios ni en los SUNC, para los que habrá que tener en cuenta lo dispuesto en la legislación estatal.

Por su parte, los artículos 74 bis y siguientes, prevén la posibilidad de que existan áreas con destino en su totalidad a viviendas protegidas que el Principado y el ayuntamiento afectado podrán convenir en atención a las necesidades de vivienda del Concejo. Sobre dichas áreas conviene advertir lo siguiente:

- Se admiten sobre cualquier tipo de suelo incluso el no urbanizable susceptible de reclasificación si carece de valores paisajísticos, culturales, ambientales o de cualquier otra índole que pudieran exigir la preservación de su transformación.

- El hecho de que la totalidad del área se vaya a destinar a vivienda protegida no parece cohonestarse con el espíritu de la legislación estatal, para la que, cuando regula las reservas, en todo caso debe quedar garantizada que la distribución de su localización sea respetuosa con el principio de cohesión social. Cohesión a la que no parecen responder las citadas áreas.

Ejemplo claro de continua modificación legislativa en la materia es la Comunidad Autónoma de Canarias, cambiando tanto los porcentajes como, sobre todo, los conceptos sobre los que aplicar los mismos (suelo residencial útil, aprovechamiento, edificabilidad residencial). Presenta como singularidad la de los municipios de preferente localización de viviendas sujetas a un régimen de protección. El artículo 26 de la Ley de Vivienda señala que los Planes Insulares de Ordenación y, en su caso, los Planes de Vivienda, determinarán dichos municipios atendiendo, especialmente, a las necesidades de las áreas metropolitanas y capitales insulares, los núcleos urbanos de nueva creación o en expansión, y las zonas turísticas. En cualquier caso, los planes de vivienda establecerán un porcentaje de vivienda a ejecutarse en municipios que no tengan el carácter de localización preferente.

La Ley 5/1999, de 8 de abril, de Urbanismo de Castilla y León en su redacción inicial no concretó un porcentaje de reserva en materia de vivienda protegida, aunque se preocupó por el fomento de la cohesión social y para municipios de 20.000 o más habitantes sí habló de un índice de variedad urbana para los sectores de
SUNC y SUBLE, consistente en una reserva de suelo para usos no predominantes.

La Ley 10/2002, de 10 de julio, que modifica la anterior, realiza la primera reforma del art. 38.2 y ya cita entre los usos no predominantes la edificación de viviendas de protección:

- Opcional en el SU.

- Obligatoria en el SUBLE. En este momento referido al porcentaje de aprovechamiento que debía destinarse a vivienda con algún régimen de protección (10\% para el delimitado y $30 \%$ para el no delimitado).

La Ley 13/2005, de 27 de diciembre, de medidas financieras, incorpora las siguientes novedades:

- El porcentaje queda referido a la edificabilidad residencial.

- Para el SUNC la reserva deja de ser opcional y se impone con un $10 \%$.

- Se diferencia entre municipios con PGOU y sin plan para aplicar los distintos porcentajes.

La Ley $4 / 2008$, de 15 de septiembre, de medidas sobre urbanismo y suelo, contiene la normativa vigente en la materia tal y como se expresa en el cuadro general.

Por su parte la ley catalana refiere la reserva al techo residencial de nueva implantación. Los apartados 4 y 5 del art. 57, que a continuación se recogen, especifican qué se entiende por tal techo.

"4. A los efectos del cálculo de las reservas mínimas obligatorias que establece el apartado 3 , es techo residencial de nueva implantación el techo destinado a vivienda, tanto de manera exclusiva como si se admite indistintamente con otros usos, que prevea el plan de ordenación urbanística municipal para los sectores de suelo urbanizable y para los polígonos de actuación urbanística en suelo urbano no consolidado y los sectores sujetos a planes de mejora urbana que tengan por objeto alguna de las finalidades a que se refiere el artículo 70.2.a. No se considera en ningún caso techo residencial de nueva implantación y no computa en el cálculo:

a) El techo correspondiente a las construcciones con uso residencial existentes en dichos sectores o polígonos.

b) El techo de los sectores con planeamiento urbanístico derivado y con proyecto de reparcelación o aprobados definitivamente de conformidad con el planeamiento anterior, en los que rigen las determinaciones del plan urbanístico derivado aprobado. 
5. Los alojamientos dotacionales integrados en el sistema urbanístico de equipamientos comunitarios no computan como techo residencial a efectos del cumplimiento de los estándares de reserva mínima siguientes:

a) De vivienda de protección pública, en los términos regulados en el apartado 3 de este artículo y el apartado 3 de la disposición transitoria tercera.

b) De sistemas urbanísticos de espacios libres públicos y de equipamientos comunitarios, en los términos regulados en los artículos 58.1.f, 5 y 7 , 65.3 y $5,70.7$ y 8 y $100 . "$

El 5 de diciembre de 2018 la Subcomisión de Urbanismo del municipio de Barcelona aprobó una Modificación puntual del Plan General Metropolitano para la obtención de vivienda de protección pública en el suelo urbano consolidado de Barcelona. El objetivo era la obtención de VPP en actuaciones edificatorias de nueva construcción y gran rehabilitación ${ }^{10}$ en SUC cuyas parcelas tengan un techo urbanístico potencial de vivienda plurifamiliar superior a $600 \mathrm{~m}^{2}$.

La apertura que esta modificación supuso para el SUC en materia de reservas de suelo para VPP, se generalizó al año siguiente en todo el territorio autonómico con el Decreto-ley $17 / 2019$, en la nueva redacción que dio al apartado 6 del art. 57 de su vigente ley urbanística, al decir que:

"[...] El plan tiene que determinar la localización de estas reservas mediante la calificación de suelo de vivienda de protección pública en suelo urbano consolidado, o no consolidado no incluido en sectores de planeamiento derivado. En sectores en suelo urbano no consolidado o urbanizable delimitado, el plan tiene que determinar el porcentaje de techo que el planeamiento derivado debe destinar a las reservas mencionadas. El planeamiento tiene que establecer los plazos para iniciar y para acabar la construcción de las viviendas."

Por otra parte, la disposición final cuarta del citado Decreto Ley 17/2019 prevé la aprobación por el Gobierno, en el plazo de 1 año desde su entrada en vigor, del Plan territorial sectorial de vivienda $^{11}$ en méritos del cual los porcentajes mínimos vistos en el cuadro se incrementarían en los municipios incluidos en áreas de demanda residencial fuerte y acreditada, con un mínimo del $50 \%$ en SUBLE delimitado y del $40 \%$ en SUNC (reducible al $30 \%$ si fuera necesario para

\footnotetext{
10 Ambos conceptos son definidos en el artículo 285ter de la
} Normativa Urbanística del Plan General. garantizar la viabilidad económica de la actuación). En ambos casos, la mitad de la reserva debe destinarse a viviendas en régimen de alquiler.

Sobre la legislación extremeña en la materia se pueden hacer las siguientes apreciaciones:

1. La regulación sobre reserva de suelo para VPP se recoge en dos disposiciones normativas:

- La Ley 11/2018, de 21 de diciembre, de ordenación territorial y urbanística sostenible (en adelante LOTUS), que en su Exposición de Motivos manifiesta como

"en ausencia de otras determinaciones, la reserva de vivienda protegida se establece cumpliendo los requisitos de la Ley estatal, pero que el verdadero peso de su implantación en la ciudad debe ser establecido por los planes de vivienda autonómicos, porque los municipios son los verdaderos conocedores de sus necesidades".

- La Ley 11/2019, de 11 de abril, de promoción y acceso a la vivienda, que:

- Habilita a la Comunidad Autónoma para establecer las medidas pertinentes para crear reservas de suelo residencial con destino preferente a la construcción de VPP o para la formación de PPS (Exposición de Motivos).

- Establece que la reserva de suelo para VPP se regirá por lo dispuesto en la legislación de suelo y la ordenación territorial, en la propia Ley $11 / 2019$ y demás normativa que resulte de aplicación (artículo 57).

2. Ninguna de las vigentes leyes anteriores establece concretos porcentajes de reserva para VPP como sí hiciera la normativa anterior. Al igual que Aragón, opta por remitirse expresamente a los porcentajes establecidos en la legislación estatal. En este sentido resulta esclarecedora la disposición adicional séptima de la LOTUS que lleva por título "Exención a la reserva de vivienda protegida", cuyo contenido se recoge en el cuadro principal de la comparativa autonómica, y que establece los siguientes criterios:

- Regla general: El planeamiento debe establecer motivadamente las distintas

${ }^{11}$ A la fecha de entrega de este artículo todavía no está aprobado. 
tipologías de vivienda protegida que pueden construirse en el suelo vinculado a dicha finalidad.

- Regla especial para los núcleos base del sistema territorial.

- Régimen particularizado para una concreta actuación que permite obtener la exención de la obligación, la suspensión de dicha exención o la reducción del porcentaje mínimo estatal (esta remisión directa a la ley estatal revela que serán de aplicación los porcentajes previstos en la misma). En este procedimiento es preceptivo, aunque no vinculante, el informe de la consejería competente en materia de vivienda. Se revela, de nuevo, la clara conexión que en esta Comunidad Autónoma tienen, tanto en cuanto a la normativa como en cuanto a la gestión, los temas de urbanismo con los de vivienda.

La única legislación que cifra su porcentaje de reserva directamente sobre las viviendas es la de La Rioja, como se ha visto en el cuadro de la FIG. 2. Por su parte, Murcia refiere la reserva al aprovechamiento residencial y establece en su disposición adicional cuarta apartado 2 la reserva del $30 \%$ sin especificar si tiene el carácter de mínima.

La nueva capacidad residencial es el término que utiliza Navarra, que presenta la singularidad de que el $5 \%$ del suelo para dotaciones locales será una opción más, además de la reserva de VPP, para construir este tipo de viviendas.

Resulta cuanto menos chocante que en la Comunidad Valenciana el porcentaje de reserva para VPP sea inferior en los casos en que la edificabilidad resulta incrementada, con sólo un $10 \%$, frente al $15 \%$ que se exigirá en los supuestos en que simplemente haya una regeneración urbana (que, a priori se podría mantener con la misma edificabilidad residencial).

Castilla-La Mancha acaba de aprobar la Ley 1/2021, de 12 de febrero, de Simplificación Urbanística y Medidas Administrativas, que contiene una importante reforma del Decreto Legislativo 1/2010, afectando también al tema de las reservas de VPP, de las que hace especial mención su Exposición de Motivos, resultado muy gráfico como se vuelve la mirada hacia los PPS:

"[...] un cambio en la regulación de esta cuestión que, por un lado, considera las especialidades de nuestros pequeños municipios, la mayoría en regresión demográfica, y, por otro, busca una necesaria correspondencia entre demanda y oferta en la regulación de estos suelos a fin de evitar situaciones perniciosas en que su reserva pueda resultar sine die, creando solares faltos de edificación e incluso, antes, constituyendo una cortapisa efectiva al desarrollo de otra serie de actuaciones propias del ámbito rural, tales como pueden ser las de carácter estacional y las turísticas, sectores impulsores de la actividad económica de los municipios en él ubicados. A su vez, esta innovación se hace extensiva a los suelos públicos incluidos en los patrimonios públicos de suelo a fin de que éstos realmente sirvan para atender las demandas reales que en cada momento se presenten en los municipios de nuestra región, principalmente en los de menor tamaño, evitando situaciones de estancamiento de estos suelos y, por ende, de frustración de la realización efectiva y última de su destino."

\section{Conclusiones}

$1^{\circ} \mathrm{La}$ institución de los PMS nace con el fin de regular el mercado del suelo y su destino termina ligándose esencialmente al de la construcción de VPP, junto al que, de una u otra forma, aparecen como destinos "otros usos de interés social". Esta expresión y la laxitud con la se manifestaría la legislación autonómica, iba a permitir a los ayuntamientos utilizar - a modo de cajón de sastre-, los bienes de sus PMS para muy diferentes usos, algunos tan alejados de ese interés social y, en definitiva, del espíritu de la ley, que terminaron por provocar la aparición de una jurisprudencia "sancionadora" de dicha actuación municipal.

Entre esos usos rechazados por la jurisprudencia del Tribunal Supremo se pueden citar, entre otros muchos, la compra de un edificio para el servicio municipal de Hacienda (sentencia 7 de noviembre de 2005), los gastos derivados de la atención al servicio municipal de basuras, pago de una deuda antigua (sentencia 31 de octubre de 2001), construcción de un centro sociocultural y deportivo, construcción del edificio de archivo municipal o del vertedero municipal, adquisición de locales para centros de tercera edad, adquisición de autobuses, inversiones en centros de enseñanza, rehabilitación y acondicionamiento de la Casa Consistorial, atenciones informáticas, actividades en euskera, adquisición de vehículos o de una central de alarma para la policía municipal (sentencia 2 de noviembre 1995), etc.

$2^{\circ}$ Posteriormente se producirá un salto cualitativo cuando las leyes de las CC. AA. empezaron a regular una nueva institución cuyo objeto era 
establecer reservas específicas de suelo destinadas, directa e inexorablemente, a la construcción de VPP.

La necesidad de responder al derecho constitucional de disfrutar de una vivienda y adecuada, sin duda, justificaba una regulación de este tipo, que no daría cabida a las posibles "escapatorias" que sí se dieron con los PMS.

$3^{\circ}$ Sobre la base de ese salto iniciado por las CC. AA., el Estado establece una regulación de mínimos con el fin de mantener cierta homogeneidad en una determinación que resulta clave para garantizar un porcentaje adecuado de vivienda asequible. Básicamente contendrá dos regulaciones de interés:

- El establecimiento de porcentajes con el carácter de mínimo.

- La fijación con destino exclusivo a la construcción de VPP de, al menos, los terrenos que el ayuntamiento obtiene a consecuencia de la recuperación de las plusvalías urbanísticas. En definitiva, se pretende ser mucho más estricto -en cuanto al destino- con los suelos procedentes del beneficio que reporta la propia actuación y que de acuerdo con la Constitución deben revertir a la comunidad que con otros bienes del PMS que no proceden de ese rescate.

En este sentido, conviene recordar que la entrega de suelo con destino al PPS en el porcentaje de entre el 5 y el $15 \%$ que establece el artículo 18.1.b del TRLSyRU no admite ser sustituida por otras formas de cumplimiento del deber si se puede cumplir con suelo destinado a VPP en virtud de la reserva prevista en el artículo 20.1.b). En definitiva, esta reserva condiciona el que, por aplicación de lo dispuesto en el art. 18.1.b) último párrafo ${ }^{12}$, la entrega de suelo que constituye el rescate de las plusvalías y que se destinará al PPS, deba necesariamente destinarse a la VPP.

$4^{\circ}$ Las situaciones de crisis económica en muchas ocasiones cuestionan la utilidad de ciertas instituciones jurídicas. Así sucedió con las reservas para VPP en la crisis de 2008 que hizo que la Ley $8 / 2013$, con los claros argumentos de su Exposición de Motivos que se recogen en el apartado 2.2.2., permitiera suspender su aplicación durante cuatro años.

La situación crítica que se padece en estos momentos, o que puedan sufrirse en otros posteriores, muy posiblemente vuelva a hacer tambalear la vigencia, si quiera sea temporal, de esta institución, o, incluso, la propia utilidad de la misma.

No ofrece duda la motivación que durante años ha orientado la decisión del legislador para regular primero, la cesión de suelo para patrimonio público, luego la reserva de suelo para la construcción de vivienda protegida y, más tarde, de manera progresiva, su ampliación a otros usos. No obstante, es también evidente que la realidad socio-económica se mueve con mucha más rapidez que cualquier ley y, por supuesto, que el propio planeamiento urbanístico. Estas distintas velocidades producen inevitables desfases con los consecuentes problemas de adaptación y, especialmente, de aplicación de la normativa a la nueva realidad surgida. Con frecuencia la ley introduce rigideces indeseables en una planificación que, cada vez más, demanda posicionarse o tomar decisiones de carácter más estructural y menos determinista, en suma, tener una mayor capacidad de adaptación. En este sentido, no parece aventurado pensar que la planificación estratégica que propone la Agenda Urbana Española, y que están implementando muchos municipios mediante la elaboración de sus respectivos planes de acción local, pueda ser el instrumento necesario que permita equilibrar la protección de los intereses que defiende la institución analizada y su adaptación a las particularidades de cada pueblo y ciudad, dotándola de la flexibilidad que la misma requiere y desde la perspectiva integrada que reclaman los acuerdos internacionales.

\section{Bibliografía}

Beato Espejo, M. (1999): La Administración del Urbanismo tras la Sentencia del Tribunal Constitucional 61/1997, de 20 de marzo, dialnet.unirioja.es

BLANCO GonzÁleZ, A. (2010): La reserva de suelo con destino a viviendas de protección pública en la legislación estatal y autonómica Práctica Urbanística n. ${ }^{\circ} 90$ pág 67-101.

LóPEZ VIÑA, J. (2019): ¿Réquiem por los patrimonios municipales de suelo? ¡Viva la Constitución! El blog

\footnotetext{
12 "La legislación sobre ordenación territorial y urbanística podrá determinar los casos y condiciones en que quepa sustituir la entrega del suelo por otras formas de cumplimiento
} del deber, excepto cuando pueda cumplirse con suelo 
de espublico. Web: administracionpublica.com. 29.11.2019.

MAGUREGUI SALAS, I. (2018): Trabas y oportunidades del urbanismo para la promoción pública de viviendas. El servicio público de alojamiento: más allá de las reservas de vivienda protegida. Práctica Urbanística n. ${ }^{\circ} 151$ marzo 2018.

MeRelo AbelA, J.M. (1991): La Reforma del Régimen Urbanístico y Valoraciones del Suelo, ed. Banco de Crédito Local.

Ministerio DE VIVIENDA (2007): Ley de Suelo y gobiernos locales.

Múñoz PÉRez, D. \& Palmero Iglesias, L. \& Marí FARINós J. (2018): Estudio especial de la reserva como técnica urbanística al servicio de la política de vivienda, ed. Universitat Politècnica de València.

\section{Listado de acrónimos/siglas}

CC. AA:: $\quad$ Comunidades Autónomas

PGOU: $\quad$ plan general de ordenación urbana o urbanística

PMS: $\quad$ patrimonio municipal de suelo

PPS: $\quad$ patrimonio público de suelo

SU: $\quad$ suelo urbano

SUBLE: $\quad$ suelo urbanizable

SUC: $\quad$ suelo urbano consolidado

SUNBLE: $\quad$ suelo no urbanizable

SUNC: $\quad$ suelo urbano no consolidado

TRLSyRU: Real Decreto Legislativo 7/2015, de 30 de octubre, por el que se aprueba el Texto Refundido de la Ley de Suelo y Rehabilitación Urbana

VPO: $\quad$ viviendas de protección oficial

VPP: viviendas sujetas a algún régimen de protección pública 